\title{
In vivo Recordings from Low-Frequency Nucleus Laminaris in the Barn Owl
}

\author{
Nicolas Palanca-Castan Christine Köppl \\ Cluster of Excellence Hearing4all, Research Center Neurosensory Science and Department of Neuroscience, \\ School of Medicine and Health Sciences, Carl von Ossietzky University, Oldenburg, Germany
}

\section{Key Words}

Barn owl · Auditory brainstem · Interaural time differences · In vivo electrophysiology · Nucleus laminaris · Sound localization

\begin{abstract}
Localization of sound sources relies on 2 main binaural cues: interaural time differences (ITD) and interaural level differences. ITD computing is first carried out in tonotopically organized areas of the brainstem nucleus laminaris (NL) in birds and the medial superior olive (MSO) in mammals. The specific way in which ITD are derived was long assumed to conform to a delay line model in which arrays of systematically arranged cells create a representation of auditory space, with different cells responding maximally to specific ITD. This model conforms in many details to the particular case of the high-frequency regions (above $3 \mathrm{kHz}$ ) in the barn owl NL. However, data from recent studies in mammals are not consistent with a delay line model. A new model has been suggested in which neurons are not topographically arranged with respect to ITD and coding occurs through assessment of the overall response of 2 large neuron populations - 1 in each brainstem hemisphere. Currently available data comprise mainly low-frequency $(<1,500 \mathrm{~Hz})$ recordings in the case of mammals and higher-frequency recordings in the case of birds. This makes it impossible to distinguish between group-related adaptations and frequency-related ad-
\end{abstract}

aptations. Here we report the first comprehensive data set from low-frequency NL in the barn owl and compare it to data from other avian and mammalian studies. Our data are consistent with a delay line model, so differences between ITD processing systems are more likely to have originated through divergent evolution of different vertebrate groups.

(c) 2015 S. Karger AG, Basel

\section{Introduction}

Interaural time differences (ITD) originate when a sound comes from one side of the head, arriving at the ipsilateral ear before the contralateral one. Animals and humans rely on ITD for localization of sounds on the horizontal plane and are able to detect ITD of only a few microseconds [Joris and Yin, 2007].

Neurons in the nucleus laminaris (NL) in birds and the medial superior olive (MSO) in mammals first encode ITD in the ascending auditory system. They act as coincidence detectors, firing maximally when the phase of the inputs from both ears is the same [Goldberg and Brown, 1969; Carr and Konishi, 1990]. In order to 'tune' a neuron to a specific ITD, a multitude of mechanisms was suggested that delay the input from one side, thus creating a transmission time mismatch that is compensated for by the matching acoustic ITD [reviewed in Vonderschen and Wagner, 2014]. These mechanisms include differ-

\section{KARGER 125}

(c) 2015 S. Karger AG, Base

0006-8977/15/0854-0271\$39.50/0

E-Mail karger@karger.com

www.karger.com/bbe
Dr. Christine Köppl

Department of Neuroscience, School of Medicine and Health Sciences

Carl von Ossietzky University, Carl von Ossietzky Strasse 9-11

DE-26129 Oldenburg (Germany)

E-Mail Christine.Koeppl@uni-oldenburg.de 
ences in the length and/or myelination of input axons [Jeffress, 1948; Cheng and Carr, 2007; Seidl et al., 2010, 2014], precisely timed inhibition [Brand et al., 2002; Grothe et al., 2010], cochlear delays [Shamma et al., 1989; Day and Semple, 2011], asymmetric synaptic rise times [Jercog et al., 2010], asymmetric spectrotemporal tuning of left and right inputs [Fischer et al., 2011], and dynamic changes at the coincidence detection stage itself [Franken et al., 2015].

Data from birds support a time delay system of axonal delay lines first suggested by Jeffress [1948] that creates a topographic array of NL neurons, each responding maximally to sounds from a specific ITD and together forming a map of azimuthal space [reviewed in Ashida and Carr, 2011]. Data from mammals have resulted in an alternative model in which neurons from a given frequency band in the MSO respond maximally to a contralaterally leading ITD that lies outside the naturally heard range (defined by the animal's head size). This places the slope, rather than the peak, of the response curve in the natural ITD range. In addition, neurons in a given tonotopic band have nearly identical response curves, and derivation of a specific azimuthal location then requires a comparison of activity levels between the 2 brainstem hemispheres. This '2-channel model' has been suggested to rely on phase delays created through precisely timed inhibition [reviewed in Grothe et al., 2010].

The intuitive conclusion from these findings is that birds and mammals have evolved different ITD-processing mechanisms [Grothe and Pecka, 2014]. However, the work by Harper and colleagues [Harper and McAlpine, 2004; Harper et al., 2014] on optimal ITDcoding strategies opened up a different interpretation, suggesting that animal head size and the frequency range of coding may be the primary factors that determine the neural code. This can be tested by examining the neural organization in the relevant nuclei as a function of frequency. The barn owl is a prime candidate to address this question. The Jeffress type mechanism it uses for high-frequency ITD coding in the NL is well characterized, undisputed, and consistent with the model prediction by Harper and McAlpine [2004]. However, at frequencies below $3 \mathrm{kHz}$, this place code model is no longer the clearly optimal solution, and below $800 \mathrm{~Hz}$ a change to a population code model was predicted. Low-frequency data are scarce for the barn owl [Wagner et al., 2002, 2007; Carr and Köppl, 2004; Cazettes et al., 2014]. The aim of the present study was to obtain in-vivo recordings from the low-frequency region of the NL to test predictions of optimal coding.

\section{Materials and Methods}

\section{Experimental Animals and Preparation}

We report data from 11 adult European barn owls (Tyto alba) of both sexes and aged between 4 and 17 months. All protocols and procedures were approved by the authorities of Lower Saxony, Germany (permit No. AZ 33.9-42502-04-11/0337). Animals were anesthetized with an initial dose of ketamine $(10 \mathrm{mg} / \mathrm{kg})$ and xylazine $(3 \mathrm{mg} / \mathrm{kg})$ via intramuscular injection. Smaller doses of ketamine and xylazine were administered periodically to maintain anesthesia. The depth of anesthesia was constantly monitored via EKG recordings using intramuscular needle electrodes in a wing and in the contralateral leg. Cloacal temperature was monitored and maintained stable at $39^{\circ} \mathrm{C}$ using a homeothermic blanket system (Harvard Apparatus). The head was firmly held by cementing the skull to a small metal plate connected to a stereotaxic frame (Kopf Instruments, Tujunga, Calif., USA). The skull was opened and the cerebellum aspirated on one side to expose the surface of the brainstem for electrode placement, as guided by visual landmarks.

\section{Electrophysiology and Definition of Recording Types}

Recordings were obtained with borosilicate microelectrodes (1.2 mm outer diameter and $0.69 \mathrm{~mm}$ inner diameter) filled with either $2 \mathrm{M}$ sodium acetate or artificial cerebrospinal fluid (138 $\mathrm{mM} \mathrm{NaCl}, 2.5 \mathrm{mM} \mathrm{KCl}, 2.5 \mathrm{mM} \mathrm{CaCl}_{2}, 1 \mathrm{mM} \mathrm{MgCl}_{2}, 10 \mathrm{mM}$ HEPES, and $26 \mathrm{~mm}$ glucose). Some electrodes were additionally loaded with $5 \%$ tracer $(10,000 \mathrm{MW}$ dextran labeled with Texas Red). Typical electrode impedances were between 10 and $20 \mathrm{M} \Omega$. Electrodes were positioned under visual control and then advanced into the brainstem remotely using a piezoelectric motor (Burleigh Inchworm). Electrodes were connected to an Intra 767 electrometer (World Precision Instruments, Sunnyvale, Calif., USA).

In early experiments ( 2 owls), the electrometer was followed by a PC1 spike preconditioner (Tucker Davis Technologies, Alachua, Fla., USA) which amplified and band pass filtered $(300-10,000 \mathrm{~Hz})$ the recording. A spike discriminator (SD1; Tucker Davis Technologies) converted neural impulses into transistor-transistor logic pulses for an event timer (ET1; Tucker Davis Technologies), which recorded the timing of the pulses. In parallel, the analog waveforms were fed into a personal computer via an analog-todigital converter (DD1; Tucker Davis Technologies) with a sampling rate of $48 \mathrm{kHz}$ and a 16-bit resolution. In later experiments, we used a different hardware configuration. The PC1 spike preconditioner was kept in order to provide amplification, but the signal was then passed through a Hum Bug (Quest Scientific Instruments Inc., North Vancouver, B.C., Canada) and into a TDT RX6 multifunction processor. Band pass filtering $(50-10,000 \mathrm{~Hz})$ and spike detection were carried out after the signal had been converted from analog to digital (48-kHz sampling rate, 24-bit resolution) using a custom Matlab (vR2012b; MathWorks, Natick, Mass., USA) script.

Single-unit recordings are difficult to obtain in NL and MSO due to the small and variable amplitude of the spikes from neuronal somata [Scott et al., 2005; Funabiki et al., 2011] and the presence of a strong field potential, i.e. the neurophonic [Tsuchitani and Boudreau, 1964; Sullivan and Konishi, 1986]. In order to improve unit isolation, we used the loose-patch technique described by Peña et al. [1996]. For this, a 5-ml glass syringe was connected 
to the electrode and a slight positive pressure (corresponding to $1 \mathrm{ml}$ ) was maintained while advancing the electrode in order to keep its tip clean. When spikes were detected and the presence of a nearby cell was suspected, the positive pressure was released and, if judged necessary, a small negative pressure was applied. On many occasions, this technique greatly improved the isolation of spikes. Subthreshold events were, however, never clearly observed. Well-isolated single units could be held for 20 or more minutes, allowing the full range of measurements. However, stability was a concern, especially for single units, and isolation could be and was lost without warning. The practical result of this is that the more time-consuming measurements [characteristic delay (CD) and characteristic frequency (CF) measurements] could not always be recorded.

The type of recording (single unit, multiunit, or neurophonic) was finally defined offline using the recorded analog data. This also defined the response metric analyzed. Traces were classified as spike recordings when they presented consistent action potentials that rose above the background noise and that allowed for flagging using a fixed threshold. Single units were defined as showing no or only very few interspike intervals of $1 \mathrm{~ms}$ or below, i.e. within the refractory period. In 2 of 19 single units, the spike sorting script 'wave_clus' created by Quiroga et al. [2004] and available from https://vis.caltech.edu/ rodri/Wave_clus/Wave_clus_home.htm was used to separate the response of a single unit within a multiunit spike recording. All responses were tested for a significant neurophonic component using the method described by Köppl and Carr [2008].

\section{Stimulus Generation and Calibration}

All recordings were performed in a double-walled sound-attenuating chamber (Industrial Acoustics Corporation, Winchester, UK). Closed, custom-made sound systems were inserted into both ear canals for controlled stimulation. These systems consisted of small earphones (Yuin PK3, Sony MDR-E818) and miniature microphones (Knowles TM-3568, EM-3069, or FG-23329) calibrated using a Brüel and Kjaer microphone (4134; Naerum, Denmark) as the reference. Sound pressure levels (SPL) were then individually calibrated for each ear.

Sound stimuli could be monaural or binaural and were generated separately for both channels by custom-written software and a signal-processing device (AP2 or RX6; Tucker Davis Technologies). Stimuli were fed into the earphones via D/A converters (DD1 or RX6; Tucker Davis Technologies), antialiasing filters (FT6-2 or RX6; Tucker Davis Technologies), and attenuators (PA4 or PA5; Tucker Davis Technologies). All stimuli had a total duration of 50 $\mathrm{ms}$, including 5-ms ramps, and were presented with an interstimulus interval of $120 \mathrm{~ms}$.

\section{Data Collection Protocols and Analysis}

The best frequency (BF), i.e. the frequency that evoked the largest response, was determined by presenting a wide range of frequencies at a fixed SPL of $0-20 \mathrm{~dB}$ above the threshold as estimated audiovisually. This test was usually run with identical binaural stimulation; in some cases, however, monaural BF curves were run separately. Randomly inserted silent trials were used to determine the spontaneous rate.

To obtain an estimate of the threshold and the response saturation level, monaural rate-level curves were run at a frequency close to the BF.

\section{Frequency Threshold Curves and CF}

Frequency threshold curve (FTC) data were always obtained monaurally. Responses were recorded into a randomly presented matrix of frequencies and SPL, in steps of typically $100 \mathrm{~Hz}$ and $5 \mathrm{~dB}$, and over a range of typically $1 \mathrm{kHz}$ and $50 \mathrm{~dB}$. FTC were interpolated from this response matrix after smoothing with a locally weighted algorithm [Köppl, 1997]. For spike recordings, the threshold was defined as a response about 20 spikes/s above the spontaneous rate as determined from randomly inserted silent trials. For neurophonic data, the lowest criterion that gave a coherent curve was used. The frequency at which the criterion response was reached at the lowest SPL defined the $\mathrm{CF}$, and the corresponding SPL defined the threshold at the CF. We also derived, when possible, the $\mathrm{Q}_{10 \mathrm{~dB}}$ and $\mathrm{Q}_{40 \mathrm{~dB}}$.

\section{Best ITD and Interaural Phase Difference}

The best ITD is the ITD that evokes the largest response. The range of tested ITD was \pm 1 period at or near the $B F$, in steps of one tenth of a period. The SPL was typically fixed at 0-20 dB SPL above the threshold. For spike recordings, the mean rate was derived at each ITD tested; for neurophonic recordings, we determined the average analog amplitude. A criterion that defined significant response modulation with ITD, i.e. the presence of ITD selectivity, was adopted from Köppl and Carr [2008]. Responses that fulfilled this criterion were fitted with a cosine function at the stimulus frequency to determine the best ITD and the best interaural phase difference (IPD). The best ITD was defined as the ITD closest to $0 \mu$ ITD that elicited a maximum response.

\section{Characteristic Phase and CD}

The characteristic phase $(\mathrm{CP})$ and $\mathrm{CD}$ were derived by performing ITD tests at several different frequencies for the same unit or neurophonic site. Three to 7 frequencies were used, covering a range of $300-600 \mathrm{~Hz}$ around the CF. We determined the best IPD for each frequency as described above and entered them into a linear regression of best IPD as a function of frequency [Yin and $\mathrm{Ku}$ wada, 1983]. The y-intercept of this regression corresponds to the $\mathrm{CP}$, and the slope corresponds to the CD. CP values were collapsed into a single cycle ( -0.5 to 0.5$)$.

\section{Labeling and Histology}

Labels were placed iontophoretically at selected recording sites by passing a positive DC current through the electrode. The current amplitude and duration varied between 5 and $500 \mathrm{nA}$ and between 1 and $30 \mathrm{~min}$, respectively. This large variation is due to experimentation to find a set of parameters that resulted in small, specific labels. The set of parameters that yielded the best results was $20 \mathrm{nA}$ for $5 \mathrm{~min}$. At the conclusion of the experiment, the animal was perfused transcardially with $4 \%$ paraformaldehyde in phosphate-buffered saline in order to fix the tissue. The brain was extracted and blocked, and the brainstem was cryoprotected by immersion in 30\% sucrose in phosphate-buffered saline for $48 \mathrm{~h}$. Fifty-micrometer sections were cut using a cryostat (Leica CM 1950; Leica Biosystems, Wetzlar, Germany) and mounted in Vectashield. Any fluorescent labels were then detected and documented using a Nikon Eclipse 90i epifluorescence microscope with a digital camera attached. After that, sections were remounted and dried on gelatinized slides, counterstained with cresyl violet, dehydrated, and permanently coverslipped with DPX. All sections containing NL were then photographed under standard bright-field 


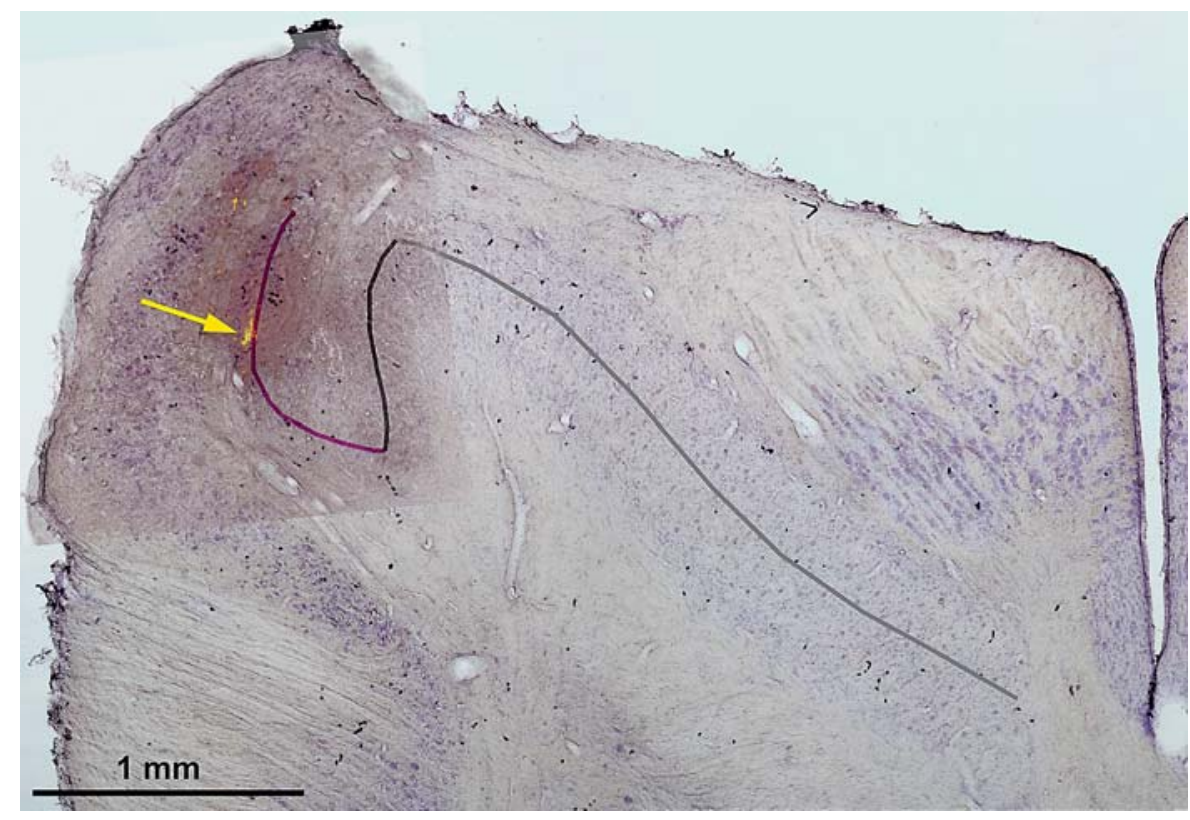

Fig. 1. Histological cross-section of the owl's brainstem, explaining the definition of the subregions and anatomical axes of the NL used to normalize the positions of the labeled sites. Dorsal is to the top, and lateral is to the left. A cresyl-violet-stained bright-field image was overlaid with an epifluorescent image of the same section, showing a fluorescent label (yellow, with an arrow pointing to it) at a recording site within the NL. The BF at this site was $400 \mathrm{~Hz}$. The entire mediolateral axis of the NL is traced by a line drawn grey in its medial, high-frequency region, black in the folded region, and purple in the caudolateral, low-frequency region [definition of these regions is after Köppl and Carr, 1997]. The mediolateral coordinate of the labeled sites was normalized as a percentage along this purple line in each individual section (in this example, $45 \%$ from the lateral edge). Note that this coordinate system virtually flattens the curved outline of the NL such that the dorsal tip of the purple line is defined as the lateral edge. Accordingly, the dorsoventral axis is then defined orthogonal to the purple line and corresponds to the thickness of the cellular layer of the NL, in line with the common definition for the medial, high-frequency region of the NL [e.g. Takahashi and Konishi, 1988]. Finally, the caudorostral position of the labeled sites was normalized to the distance determined from the total number of sections containing NL in the respective brain. illumination. The distance between the medial edge of the NL and the midline, as well as the mediolateral extent of the NL, was measured by carefully following the nucleus' shape in each section. We distinguished medial, caudolateral, and intermediate 'fold' regions [after Köppl and Carr, 1997] (fig. 1). These measurements were used to create a flattened reconstruction of the NL and to represent the locations of labeled sites in normalized coordinates on the caudorostral, mediolateral, and dorsoventral axes (fig. 1).

\section{Results}

We report a total of 129 recordings from barn owl NL, 19 of which were extracellular single-unit recordings (fig. 2a), 10 of which were spike multiunit recordings (fig. 2b), and 100 of which were neurophonic recordings (fig. 2c). An example of each type of recording is shown in figure 2. The neurophonic is an extracellular field potential that mimics the input signal [Tsuchitani and Bou- dreau, 1964; Weinberger et al., 1970]. This neurophonic potential is unusually strong in the barn owl NL [Sullivan and Konishi, 1986]. The BF recorded ranged from 100 to $3,571 \mathrm{~Hz}$, and $80 \%$ (including all single- and multiunit spike recordings) were below $3,000 \mathrm{~Hz}$. These can be considered low frequencies for the owl, since these frequencies are not represented in the main (medial) body of the NL but are rather in its folded and caudolateral regions. Thirty-five percent of the recordings corresponded to frequencies at or below $800 \mathrm{~Hz}$, which is the approximate transition frequency where a change to a 2-channel model was predicted by Harper and McAlpine [2004].

\section{Similarity of Neurophonic and Spike Responses at the Same Site}

The presence of a strong neurophonic response was consistent throughout all of the recorded regions. The neurophonic was well modulated as a function of the ITD 


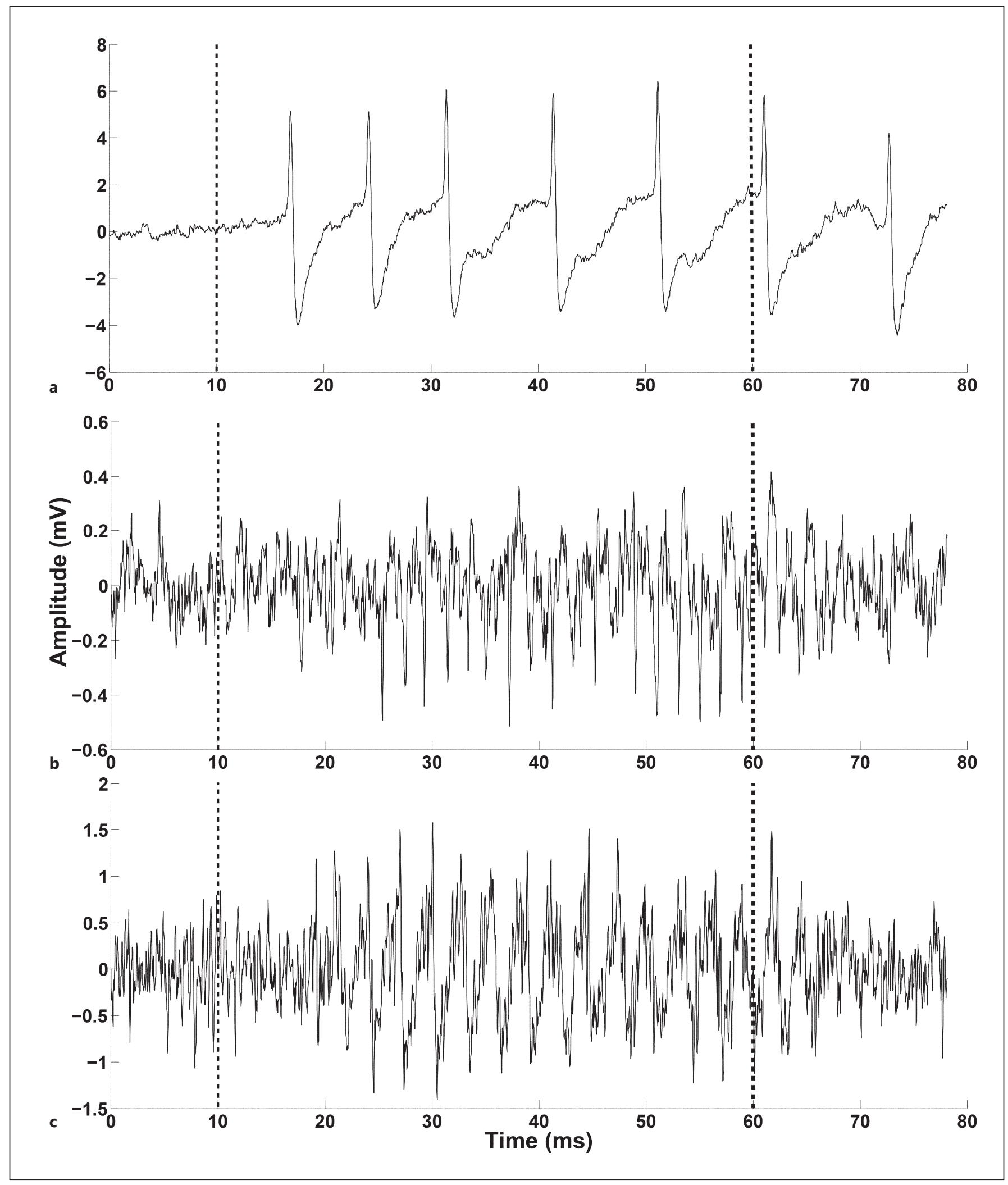

Fig. 2. Example single traces of recordings from a single unit (100-Hz BF, a), a multiunit spike recording $(250-\mathrm{Hz}$ $\mathrm{BF}, \mathbf{b})$, and a neurophonic recording $(333-\mathrm{Hz} \mathrm{BF}, \mathbf{c})$. The dashed lines indicate the stimulus window. 
Table 1. Comparison of neurophonic and spike recordings obtained in close proximity

\begin{tabular}{|c|c|c|c|c|c|c|c|}
\hline \multirow{2}{*}{$\begin{array}{l}\text { Distance, } \\
\mu \mathrm{m}\end{array}$} & \multicolumn{2}{|c|}{ Spike recording } & \multicolumn{2}{|c|}{ Neurophonic recording } & \multirow{2}{*}{$\begin{array}{l}\text { Frequency } \\
\text { difference, } \\
\mathrm{Hz}\end{array}$} & \multirow{2}{*}{$\begin{array}{l}\text { Best ITD } \\
\text { difference, } \\
\mu \mathrm{s}\end{array}$} & \multirow{2}{*}{$\begin{array}{l}\text { Phase } \\
\text { difference, } \\
\text { cycles }\end{array}$} \\
\hline & $\begin{array}{l}\text { frequ } \\
\mathrm{Hz}\end{array}$ & $\begin{array}{l}\text { best ITD, } \\
\mu \mathrm{s}\end{array}$ & $\begin{array}{l}\text { frequency, } \\
\mathrm{Hz}\end{array}$ & $\begin{array}{l}\text { best ITD, } \\
\mu \mathrm{s}\end{array}$ & & & \\
\hline $\mathbf{0}$ & 100 & 1,232 & 100 & 5,000 & $\mathbf{0}$ & 3,768 & 0.38 \\
\hline 120 & 200 & 1,185 & 450 & 1,050 & 250 & 135 & 0.23 \\
\hline 150 & 333 & 900 & 400 & 259 & 67 & 641 & 0.20 \\
\hline 150 & 333 & 935 & 400 & 1,000 & 67 & 065 & 0.09 \\
\hline 0 & 400 & 1,475 & 333 & 900 & 67 & 575 & 0.29 \\
\hline 70 & 500 & -500 & 500 & -600 & 0 & 100 & 0.05 \\
\hline 0 & 714 & 420 & 714 & 280 & 0 & 140 & 0.01 \\
\hline $\mathbf{0}$ & 1,176 & -35 & 1,176 & 085 & 0 & 050 & 0.14 \\
\hline $\mathbf{0}$ & 1,250 & 149 & 1,250 & -80 & 0 & 229 & 0.29 \\
\hline 0 & 2,000 & 174 & 2,000 & 150 & 0 & 024 & 0.05 \\
\hline 0 & 2,632 & 197 & 2,632 & 190 & 0 & 7 & 0.02 \\
\hline 0 & 3,448 & -16 & 3,448 & -29 & 0 & 13 & 0.04 \\
\hline
\end{tabular}

Values in bold represent single units.

when the electrode was judged to be inside the cellular region of the nucleus. To test how well neurophonic responses reflected the local neural activity, we analyzed 12 cases of paired recordings where spikes and neurophonics were obtained with the same electrode in close proximity (within $0-150 \mu \mathrm{m}$ of each other). We determined any mismatch between their best IPD and BF (table 1). The best IPD (as opposed to the best ITD) was chosen to account for the difference in period and thus maximize comparability across sites of very different $\mathrm{BF}$. The $\mathrm{BF}$ of the 12 paired recording sites ranged from 100 to $3,500 \mathrm{~Hz}$. Six pairs had best IPD mismatches of 0.1 cycles or less. The remaining 6 had best IPD mismatches between 0.14 and 0.38. These larger IPD mismatches were more often seen at low-frequency $(<500 \mathrm{~Hz})$ recording sites than at high-frequency ones ( $4 / 7$ and $2 / 5$, respectively). Recording sites below $500 \mathrm{~Hz}$ also showed larger mismatches between spike and neurophonic BF, i.e. up to $63 \%$ of the ipsilateral CF. We suggest that the increased probability of an appreciable mismatch is due to the higher neuron density in low-frequency regions of the NL [Köppl and Carr, 1997].

\section{CF, Thresholds, and Tuning}

$\mathrm{CF}$ values ranged from 150 to $3,500 \mathrm{~Hz}$. Thresholds were variable, ranging from 13 to $57 \mathrm{~dB}$ SPL (fig. 3a). The sharpness of tuning, as measured by the $\mathrm{Q}_{10 \mathrm{~dB}}$, ranged from 1.5 to 15 , with slightly lower values at low frequencies (fig. 3b). The spontaneous rate of single units ranged from 4 to 200 spikes/s (fig. 3c). Ipsi- and contralateral thresholds and $\mathrm{Q}_{10 \mathrm{~dB}}$ values were not significantly different (Wilcoxon's signed-rank test, $\mathrm{p}=0.767$ and $\mathrm{p}=0.794$, respectively, $\mathrm{n}=25$ for the threshold and $\mathrm{n}=10$ for the $\left.\mathrm{Q}_{10 \mathrm{~dB}}\right)$. There were, however, significant mismatches between the CF obtained with ipsi- and contralateral stimulation (Wilcoxon's signed-rank test, $\mathrm{p}=0.049, \mathrm{n}=26$ ). The extent of these CF mismatches is shown in figure $4 \mathrm{a}$, expressed as a percentage of the ipsilateral CF. We explored whether these differences in $\mathrm{CF}$ had any predictive value regarding the best ITD. For this, group delay data from the auditory nerve of the barn owl [fit shown in fig. 10A of Köppl, 1997] were used to predict the latency difference due to the CF mismatch and compare it to the best ITD for that particular recording site (fig. 4b). There was no correlation between the two (Spearman's rank correlation, $\mathrm{p}=0.156, \mathrm{n}=22$ ). Indeed, not even the sign of the CF difference consistently predicted the correct side leading.

\section{Best ITD and IPD Distribution}

Best ITD values ranged from 0 to $5,000 \mu$ s contralaterally leading and to $-1,000 \mu$ s ipsilaterally leading. There was a bias towards contralaterally leading ITD, consistent with previously reported data, especially at lower frequencies (fig. 5a). The range of ITD represented clearly increased with decreasing frequency. Harper and McAlpine [2004] defined 3 frequency ranges with different predicted optimal systems for the barn owl given its head size: $>3,000 \mathrm{~Hz}$ (Jeffress-like place code predicted as optimal), $800-3,000 \mathrm{~Hz}$ (ambiguous), and $<800 \mathrm{~Hz}$ (2-chan- 

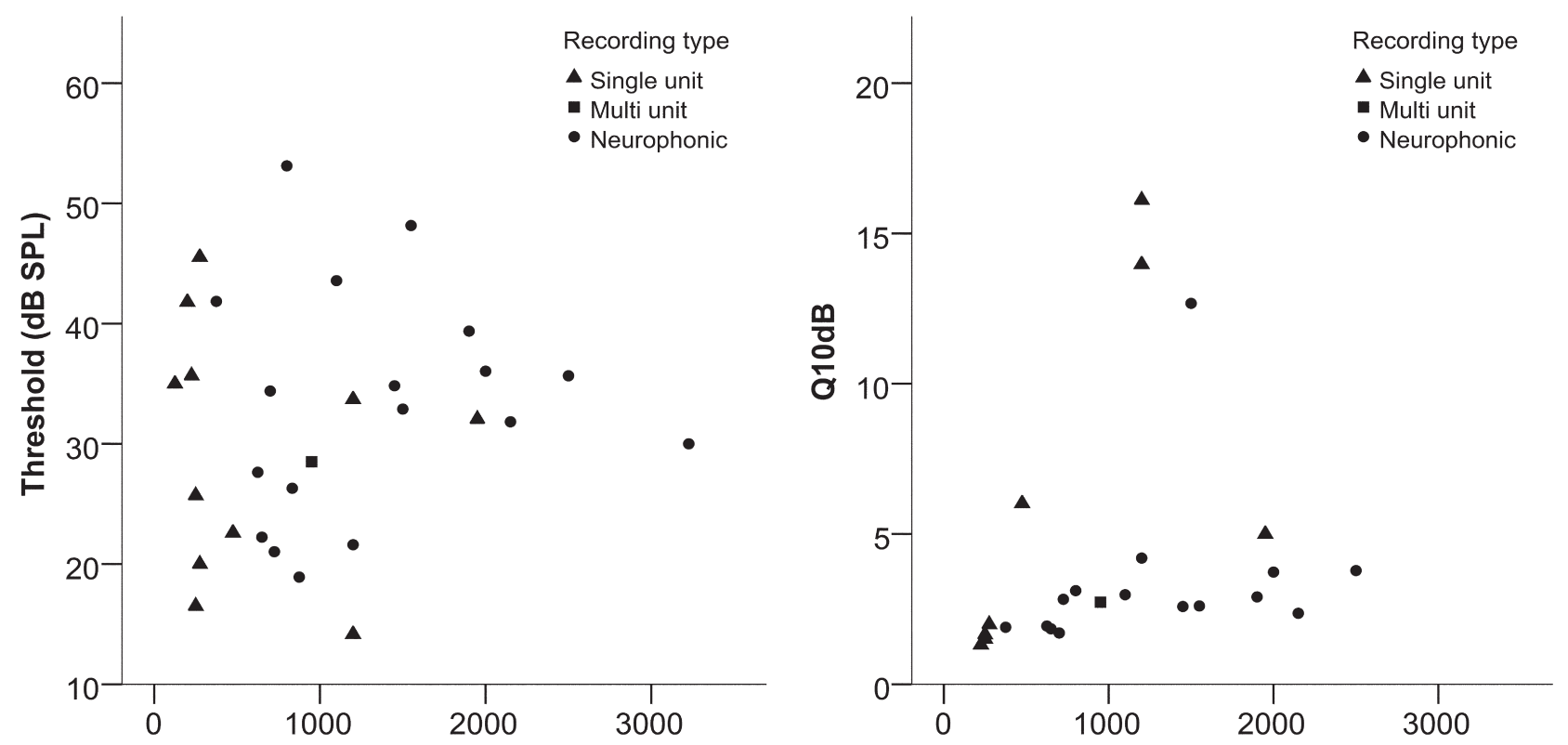

a

Frequency $(\mathrm{Hz})$

b

Frequency $(\mathrm{Hz})$

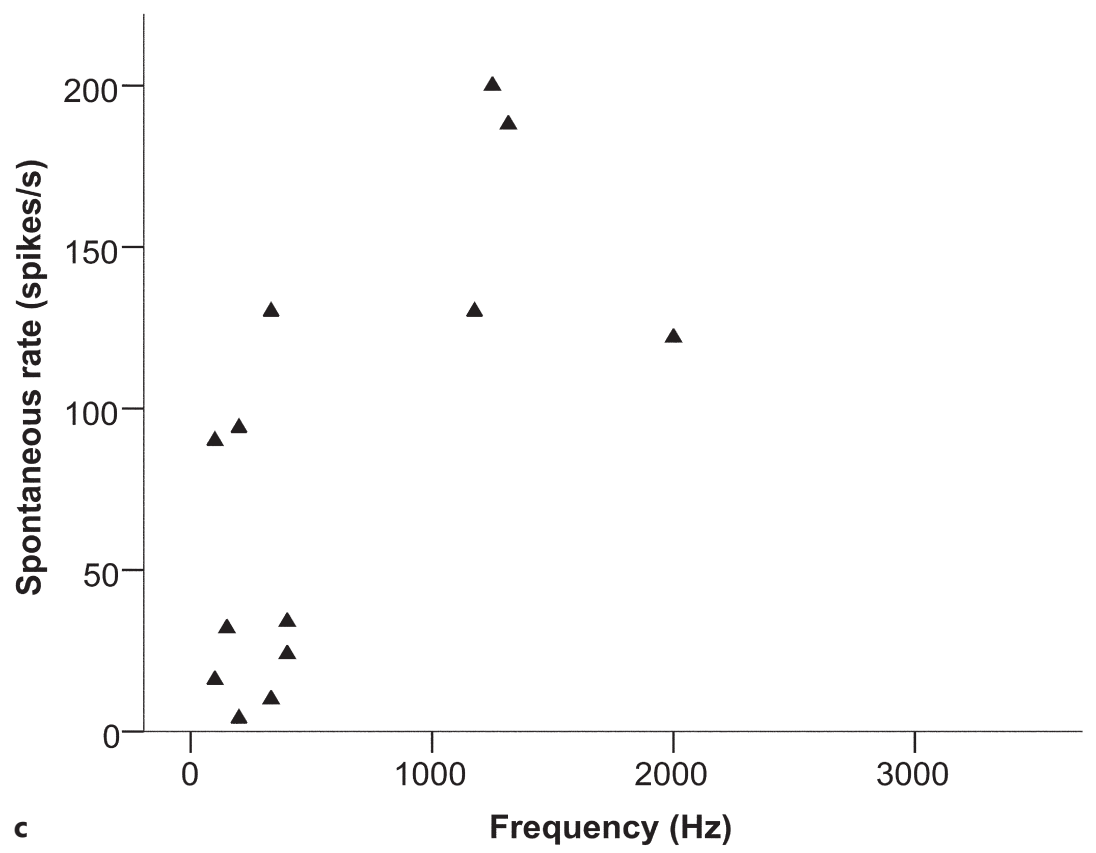

Fig. 3. a Threshold (mean of ipsi- and contralateral when available, and ipsi- or contralateral value when only one of them was available) as a function of frequency (CF or BF or audiovisually determined $\mathrm{BF}$, in this order of priority). $\mathbf{b} \mathrm{Q}_{10 \mathrm{~dB}}$ values (mean of ipsi- and contralateral when available, and ipsi- or contralateral value when only one of them was available) as a function of frequency (defined as in a). c Single-unit spontaneous rate as a function of frequency. 


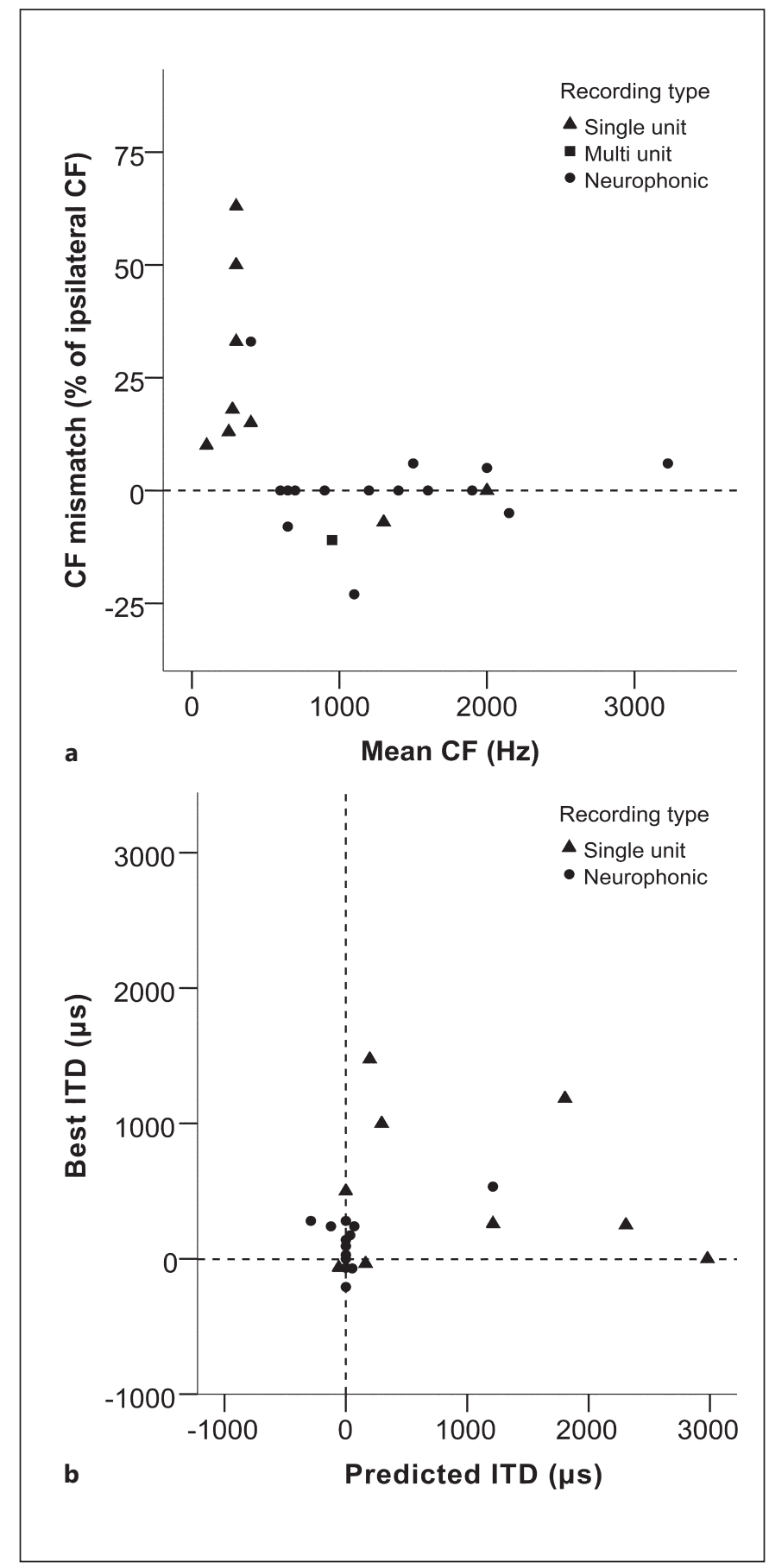

Fig. 4. a CF mismatch, expressed as a percentage of the ipsilateral $\mathrm{CF}$, as a function of the mean CF. The dashed line marks the 0 value, i.e. no mismatch. $\mathbf{b}$ Comparison between the best ITD predicted by the CF mismatches and the actually measured best ITD. The dashed lines mark the 0 values. nel population code predicted as optimal). Figure $5 \mathrm{c}$ shows the median and range of best ITD values within these 3 frequency ranges for the different recording types. There were no significant differences between recording types in any of these frequency ranges (Kruskal-Wallis test, $\mathrm{p}>0.07$ in all cases); therefore, the lumped distribution is also shown in figure $5 \mathrm{~d}$.

Best IPD values generally ranged from -0.5 to 0.5 (fig. 5b). We found only 3 best IPD values outside the pi limit, a range corresponding to half the period of the stimulus frequency and equivalent to the maximum best ITD that can be generated using phase delays [Vonderschen and Wagner, 2014]. The distribution of best IPD was homogeneous, with no clear clustering around specific values at different frequencies and no frequency-dependent distribution across all frequencies (fig. 5b). There were no significant differences between recording types in any of the frequency ranges (Kruskal-Wallis test, $\mathrm{p}>0.27$ in all cases).

Due to the nature of ITD sensitivity, neural response modulation is cyclical. Thus, with our usual ITD testing range of \pm 1 period of the stimulus frequency, we expected to see 2 response maxima - one of which would usually lie in the ipsilaterally leading range of ITD and the other which would be in the contralaterally leading range. This causes the best ITD and IPD values to be ambiguous, since it cannot be resolved which of the 2 possibilities truly corresponds to the ITD conveyed by the neuron's inputs. For our analysis, we took the peak closest to 0 as the physiologically relevant one. However, only additional measurements such as taking responses at several different frequencies and determining the common CD (see Materials and Methods) can truly resolve this ambiguity. Among our 129 recording sites, 33 were extensively tested in this way (an example shown in fig. 6). Of those, only 2 cases emerged in which the disambiguated response maximum was not the one closest to 0 .

\section{$C P$ and $C D$}

The relationship between phase and frequency can usually be expressed using a linear equation (an example is shown in fig. 6c). The slope of this equation is the $\mathrm{CD}$ and the $y$-intercept is the CP. Pure time-delay systems like the Jeffress model are expected to show CP close to 0 or 1. Other values indicate that there is some phase delay contribution [Vonderschen and Wagner, 2014].

The distribution of $\mathrm{CD}$ values was very similar to the best ITD distribution in that it was strongly contralaterally biased, it was distributed homogeneously, and it showed a greater spread at lower BF (fig. 7a). Phase-fre- 


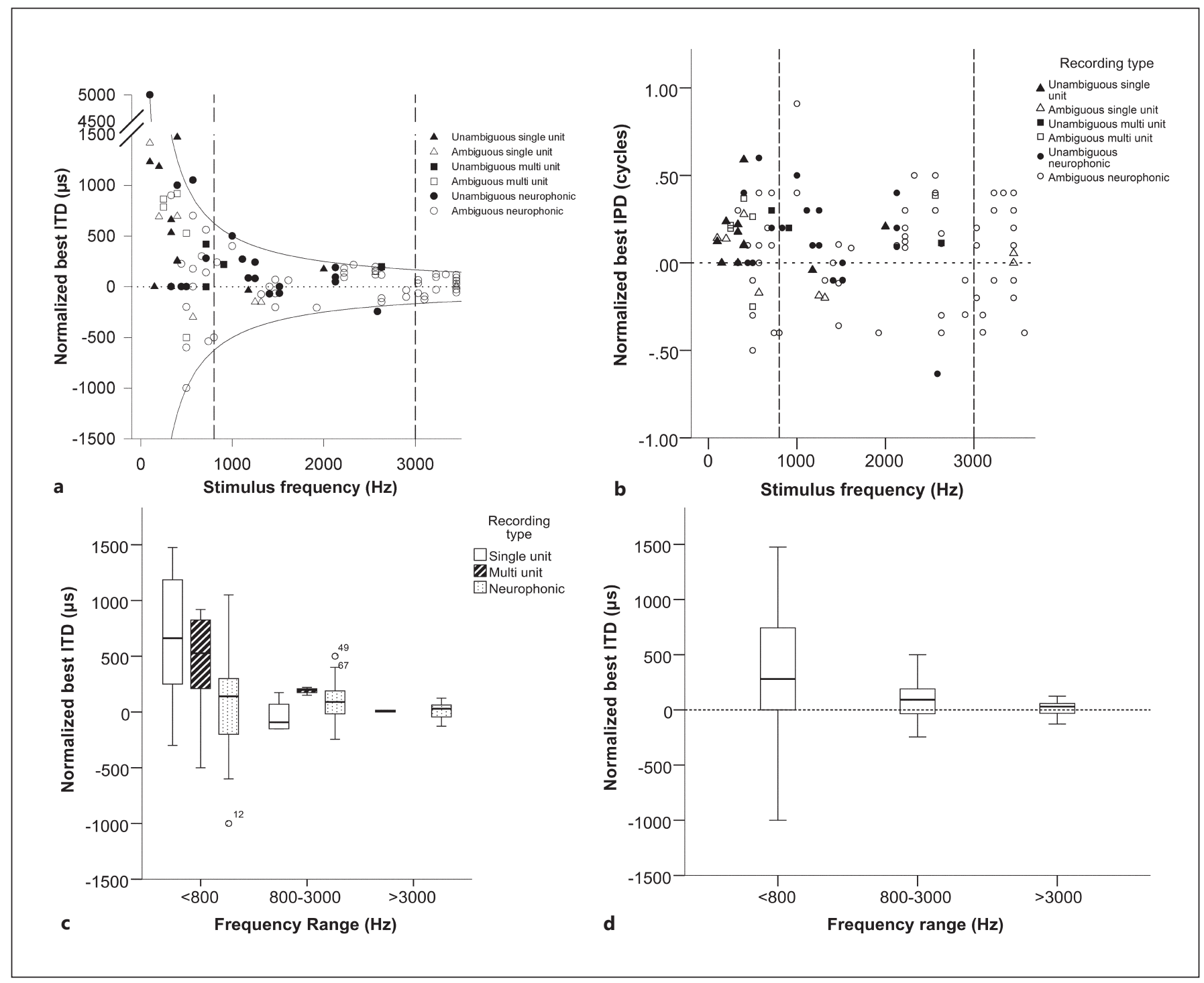

Fig. 5. a Best ITD as a function of stimulus frequency. Best ITD is shown normalized such that positive values represent contralaterally leading stimuli and negative ones represent ipsilaterally leading stimuli. The solid lines represent the pi limit; 0 ITD is highlighted by a dotted line. Vertical dashed lines divide the $<800,800$ 3,000 , and $>3,000 \mathrm{~Hz}$ frequency ranges. $\mathbf{b}$ Best IPD as a function of stimulus frequency. Best IPD is also shown normalized and 0 IPD is highlighted by a dotted line. Vertical lines divide the $<800,800-$ 3,000 , and $>3,000 \mathrm{~Hz}$ frequency ranges. In addition, closed sym-

bols represent unambiguous values where the laterality was verified by determining the common $\mathrm{CD}$ across a range of frequencies (e.g. in fig. 6); open symbols represent ambiguous values. c, d Box plots of best ITD values within the $<800(\mathrm{n}=41), 800-3,000(\mathrm{n}=$ $62)$, and $>3,000 \mathrm{~Hz}(\mathrm{n}=25)$ frequency ranges. Boxes show interquartile ranges with the median indicated by a line, and whiskers represent maximum and minimum values. $\mathbf{d}$ All of the recording types combined for each of the 3 frequency ranges.

quency relations were quite diverse (fig. $7 \mathrm{~b}$ ). Twenty of 31 cases showed a CP close to 0 or 1 (within \pm 0.15 , indicated by the dashed lines in fig. 7b), which indicates a CD close to the peaks of the ITD curves. Seven cases showed intermediate $\mathrm{CP}$, indicating that the $\mathrm{CD}$ occurred at some point along the slopes of the ITD curves. Lastly, 4 of 31

cases had CP values close to 0.5 (within \pm 0.15 ), which indicates that the CD occurred near the troughs of the ITD curves. The distribution of CP did not seem to depend on the frequency. There were no significant differences in $\mathrm{CD}$ or CP between the recording types (Kruskal-Wallis test, $\mathrm{p}>0.14$ in all cases). 


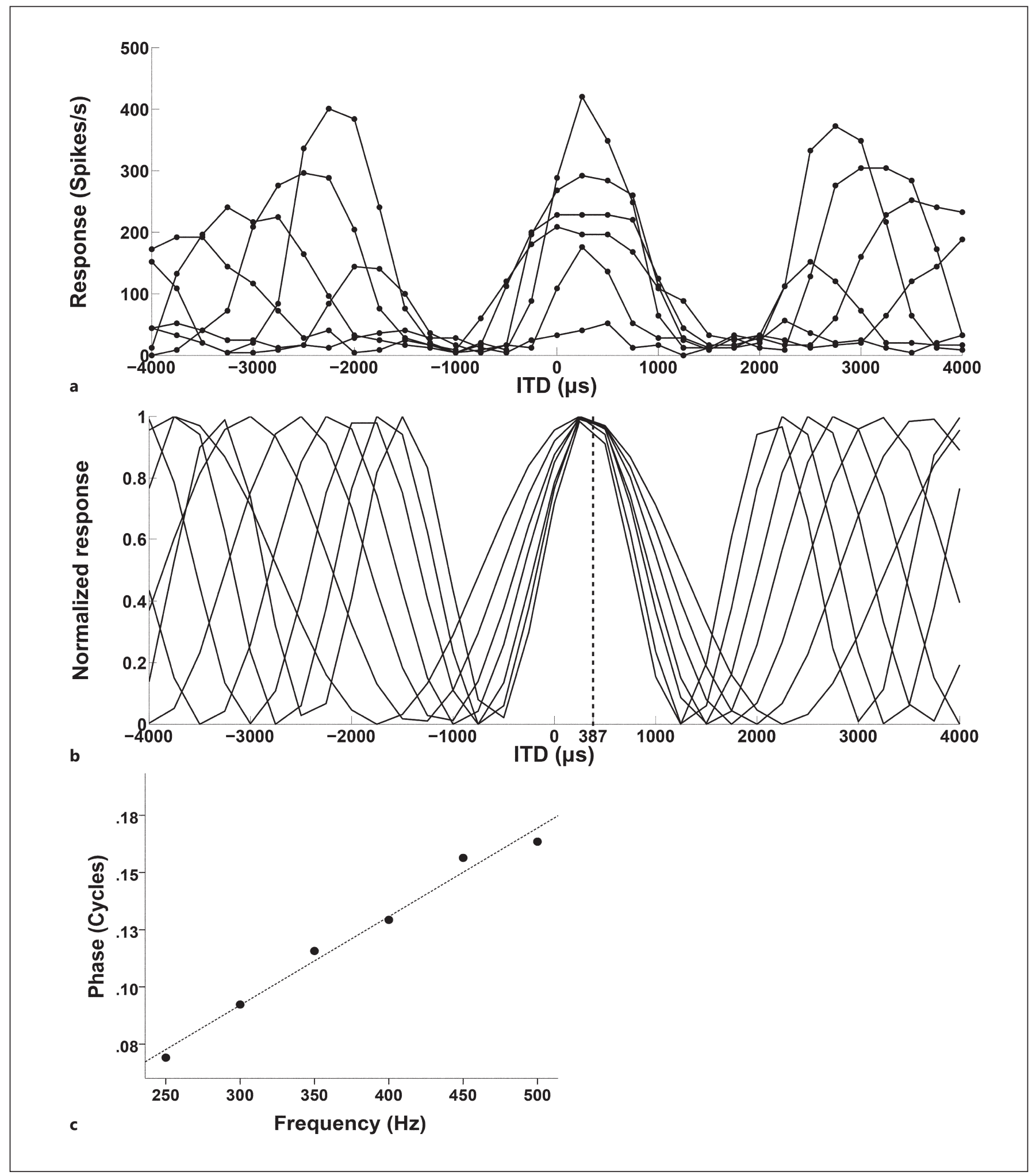

Fig. 6. Example of a set of multiple ITD curves used to determine the $\mathrm{CD}$ of a single unit with a BF of $300 \mathrm{~Hz}$, a CD of $387 \mu$ s contralaterally leading, and a $\mathrm{CP}$ of -0.02 . a Mean discharge rate as a function of the ITD for each of the tested frequencies $(250-500 \mathrm{~Hz}$ in $50-\mathrm{Hz}$ steps). b Cosine fits for each of the tested frequencies. c Resulting phase-frequency plot, fit with a linear regression. The slope of this fit is the $\mathrm{CD}$ and the $\mathrm{Y}$-intercept represents the $\mathrm{CP}$. 


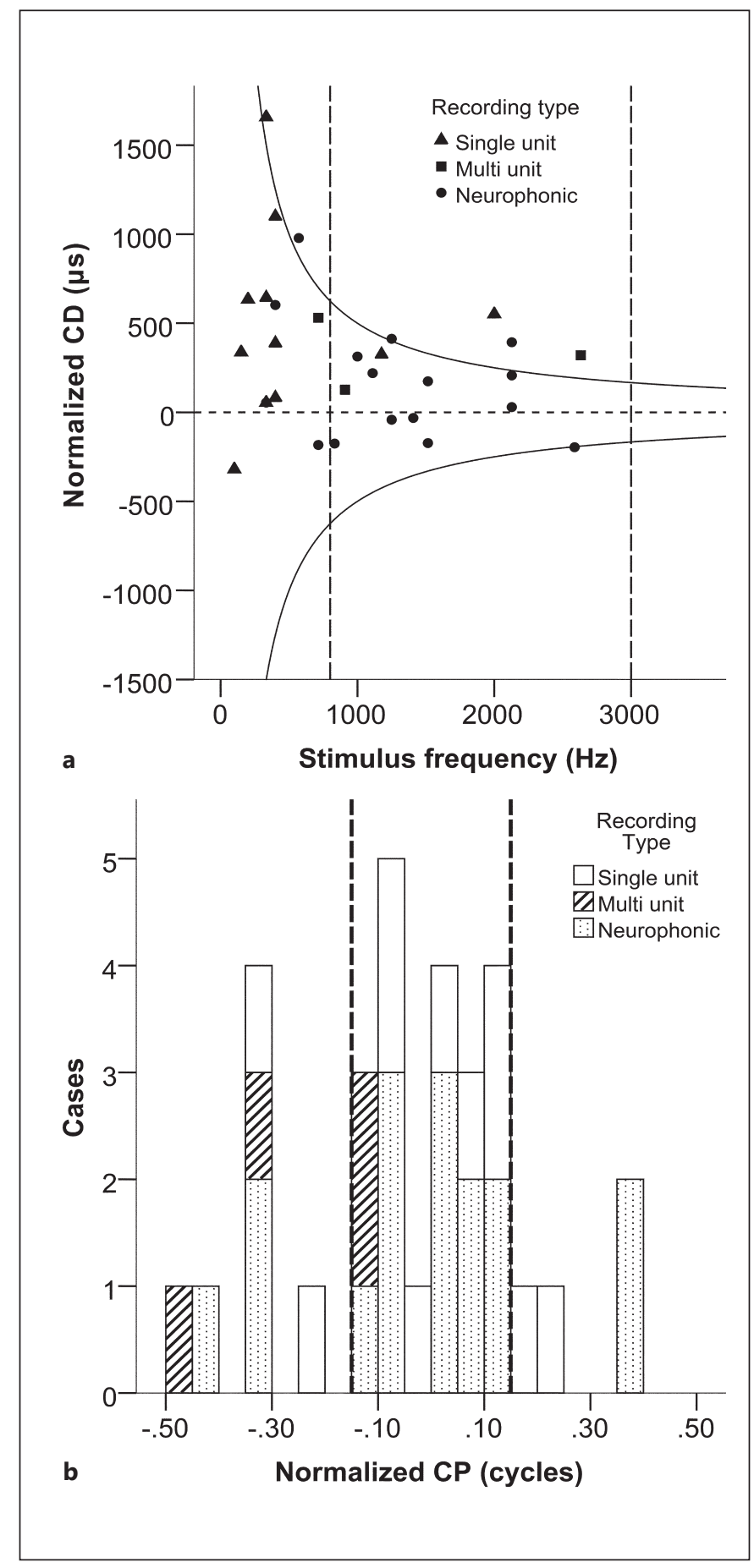

Fig. 7. a CD plotted as a function of the stimulus frequency closest to the BF. CD is shown normalized such that positive values represent contralaterally leading stimuli and negative ones represent ipsilaterally leading values. Different symbols represent different types of recordings, as in figure 3 . Solid lines represent the pi limit; $0 \mathrm{CD}$ is highlighted by a dashed line. Vertical dashed lines divide the $<800,800-3,000$, and $>3,000 \mathrm{~Hz}$ frequency ranges. b Histogram showing the $\mathrm{CP}$ distribution, with a bin width of 0.05 cycles. Dashed lines highlight the range of \pm 0.15 cycles around 0 .

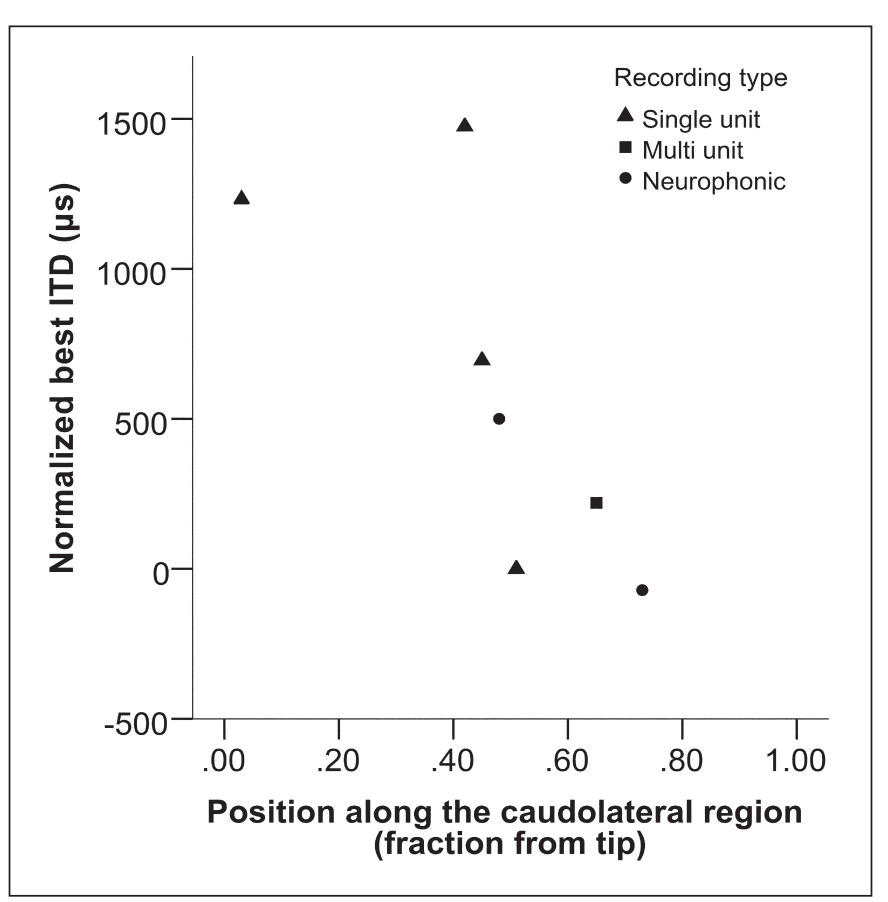

Fig. 8. Best ITD recorded immediately before dye iontophoresis as a function of the position of the recovered label. Position is expressed as a fraction of the distance from the tip (i.e. lateral edge) along the caudolateral, low-frequency region of the NL (refer to the purple line in fig. 1).

\section{Anatomical Position of the Labeled Recording Sites}

A total of 7 recording sites from 5 different NL were confirmed by labeling and all were located in the caudolateral, low-frequency region of the NL (see fig. 1 for definition of the regions). In the cases where 2 sites were labeled in the same NL, relative entry points of the respective electrode penetrations were used to unambiguously assign the 2 labels. Four labels were deposited at sites where a single unit had been recorded; the label, however, was extracellular in all cases and radiated over $18-240 \mu \mathrm{m}$ around the injection center.

Our data showed no significant correlations between the best ITD and the caudorostral or dorsoventral coordinates of the label (Spearman's rank correlation, all $\mathrm{p}>$ $0.05, \mathrm{n}=7)$. However, the mediolateral coordinate showed a significant correlation with the best ITD (Spearman's rank correlation, $\mathrm{p}=0.003$, correlation coefficient $\rho=$ $-0.93, \mathrm{n}=7$; fig. 8 ). The best ITD decreased with the distance from the tip of the caudolateral portion, i.e. more medial positions showed smaller best ITD. Regarding tonotopic organization, we found 2 weak (not statistically significant) trends in the caudorostral and mediolateral axes, with the frequency increasing rostrally and laterally. 


\section{Discussion}

The data reported here constitute the first comprehensive data set of in vivo recordings from the lower frequency regions of the barn owl NL. Their relevance is 2 -fold. First, they allow a more direct comparison of the physiology of the barn owl NL with the mammalian MSO, since they cover an overlapping frequency range. Second, they allow us to examine which of the existing ITD-processing models is supported best. We first discuss a technical point regarding the validity of including neurophonic recordings in addition to unit recordings. We then argue that the data are consistent with previous studies in both owls and other birds and they therefore provide no evidence for a fundamental change in ITD coding between low and high frequencies in the barn owl.

\section{Validity of the Neurophonic as a Proxy for NL \\ Responses}

Neurophonic responses in the NL and MSO show a clear ITD sensitivity [Wernick and Starr, 1968; Sullivan and Konishi, 1986] and thus reflect the defining characteristic of NL and MSO neurons. Direct, empirical comparisons between local neurophonic and unit responses are rare but have shown good correspondence [Köppl and Carr, 2008]. However, the source of the neurophonic is not entirely clear and very probably differs depending on morphological organization [Kuokkanen et al., 2010; McLaughlin et al., 2010; Goldwyn et al., 2014]. Specifically, the bipolar orientation of dendrites and the associated spatial segregation of ipsi- and contralateral inputs that is typical of the mammalian MSO and the chicken NL have repeatedly been suggested to generate a bipolar electric field [e.g. Galambos et al., 1959; Schwarz, 1992]. Recently, Goldwyn et al. [2014] showed that, depending on the distance from the cell body layer, the neurophonic potential with this particular anatomical configuration may actually be larger for the out-of-phase compared to the coincident arrival of ipsi- and contralateral inputs. In a typical test for ITD selectivity, this would lead to erroneous assignment of the best ITD, depending on the electrode's location along the dipole field. We argue that this prediction does not apply to our recordings from the owl's caudolateral NL because the morphology of this region is unique and resembles neither the chicken NL nor the MSO, nor, indeed, the medial part of the owl NL [Köppl and Carr, 1997]. Neurons in the caudolateral region are not all bipolar and those that are bipolar do not show a uniform orientation; when quantified, only $32 \%$ of those cells were oriented orthogonal to the lateral bor- der and $21 \%$ were parallel to it [Köppl and Carr, 1997]. In addition, the electrode angle in our recordings was oblique relative to this predominant bipolar dendritic plane, rather than parallel to it, as assumed in the model of Goldwyn et al. [2014]. Lastly, as our primary aim was to obtain unit recordings from the cellular area of the NL, data collection was primarily in close proximity to cells, a judgement which was confirmed by the fact that all labeled sites were found within the nucleus.

We carefully compared the responses to ITD and frequency between neurophonic and spike responses obtained in close proximity in this study. We observed an increased range of differences between such pairs in best IPD and BF at frequencies below $500 \mathrm{~Hz}$, but not any systematic bias (table 1). This increases the variability of anatomical correlations with physiology (since the BF or the best ITD of a specific low-frequency neurophonic might slightly differ compared to a single unit at the same location) but does not principally invalidate neurophonic data. Indeed, as observed previously [Köppl and Carr, 2008; Carr et al., 2009], there were no significant differences in best ITD, best IPD, CD, or CP between the populations of single-unit, multiunit, and neurophonic recordings. Thus, all of the conclusions in this paper are consistent with the single-unit data, although they comprised a minority of the sample.

\section{Evidence for Different Types of Input Delays}

The distribution of best ITD in the low-frequency region of the barn owl NL showed the same contralaterally leading bias as previously found for the higher-frequency regions of the same nucleus [Sullivan and Konishi, 1986; Carr and Konishi, 1990; Peña et al., 2001]. In addition, the best-ITD distribution within any given frequency band appeared homogeneous over its range (fig. 5a). This is in agreement with previous data on low-frequency responses in the barn owl's core of the inferior colliculus [Wagner et al., 2007]. However, an inhomogeneous representation of the ITD has been observed downstream [Cazettes et al., 2014]. A homogeneous distribution is consistent with a Jeffress type representation of the ITD, based on timedelayed inputs. In contrast, a 2-channel model, based on phase delays, predicts some degree of clustering around a specific ITD value that should decrease with increasing frequency [McAlpine et al., 2001; Brand et al., 2002; Vonderschen and Wagner, 2014]. There was clearly no clustering in our data, and many values fell near 0 . However, the overall ITD range broadened with decreasing frequency - a typical finding in both avian/crocodilian and mammalian studies [Carr et al., 2009; Bremen and 
Fig. 9. Schematic illustration of the functional topographic axes in the NL relative to our standard anatomical axes. a Known layout for the chicken NL [Köppl and Carr, 2008]. b Equivalent hypothetical layout for the low-frequency, caudolateral region of the owl NL. Both NL are shown as flattened projections (see Materials and Methods) viewed from above. Rostral is to the top, and medial is to the right. Note that the folded and medial regions of the owl NL are not included and would follow medial to the dotted line. Thin lines delineate isofrequency bands, and thick grey bars represent our histological section plane which defined the mediolateral axis. Note how each section cuts across several isofrequency bands, such that both a tonotopic gradient and a gradient in the best ITD will be predominantly observed along the mediolateral axis.

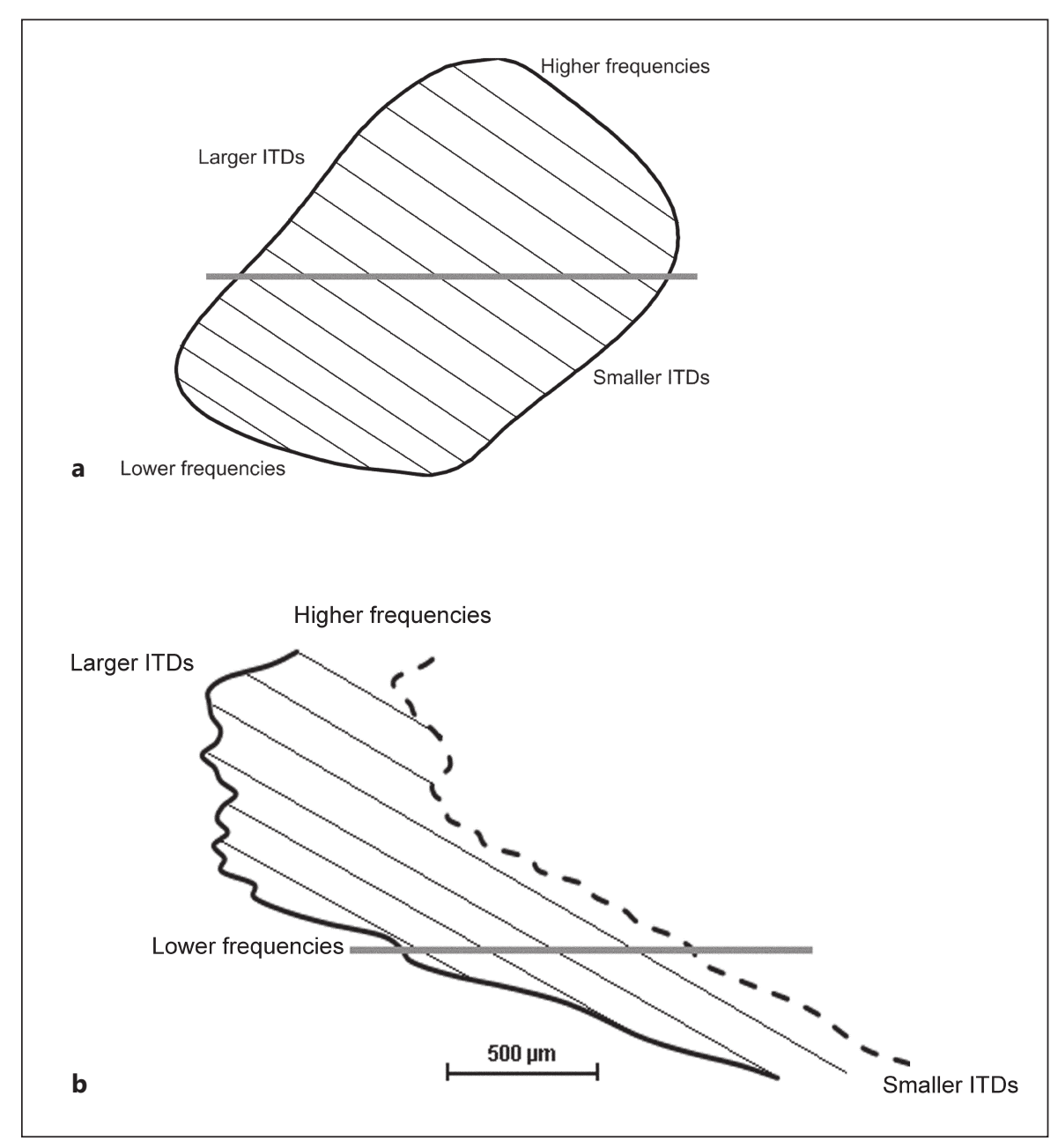

Joris, 2013]. Such broadening is not predicted by the classic Jeffress model and has thus been advanced in favor of a phase delay system, although this is quite controversial [reviewed in Joris and Yin, 2007]. Intriguingly, a recent study modeling the developmental plasticity of ITD coding circuits concluded that a similar frequency dependence of the best ITD range may result for systems based on time delays and phase delays alike [Fontaine and Brette, 2011]. Therefore, a larger dispersion of best ITD at lower frequencies has little conclusive value and is no grounds for dismissing a delay line model.

A related parameter is whether the data stay confined within the so-called pi limit, a theoretical limit for the best ITD distribution of a phase delay system [Vonderschen and Wagner, 2014] and equal to half the period of the stimulus frequency. Theoretically, the pi limit does not apply to a pure time-delay system such as the Jeffress model, where best ITD should instead be found all across the naturally occurring range, irrespectively of the frequency band. Our dataset presented only 3 points outside the pi limit, consistent with a phase-delay system and also consistent with low-frequency IC data in the barn owl [Wagner et al., 2007]. However, as pointed out by Wagner et al. [2007], even in a time-delay system, values above the pi limit are only expected to occur once the naturally heard range of ITD exceeds that limit. At low frequencies, this is never the case. Thus, again, the observed data distribution does not conclusively suggest a time delay or a phase delay system.

Finally, the stereausis model [Schroeder, 1977; Shamma et al., 1989] is based on cochlear delays and monaural inputs to the coincidence detectors that are mismatched in the CF. Our data from the low-frequency region of the owl NL do not support such an origin of delays, which is consistent with previous findings at higher frequencies in the NL [Peña et al., 2001; Fischer and Peña, 2009] and in 
the inferior colliculus [Singheiser et al., 2010]. While we did observe CF mismatches between some monaural responses in the NL, they appeared random and were not at all predictive of the measured best ITD (fig. 4). Importantly, though, these random CF mismatches could account for a phase delay component indicated by the occurrence of nonzero CP (fig. 7b), even if they are compensated by a time delay mechanism such as axonal delay lines [Day and Semple, 2011].

Topographic Representations of Frequency and ITD in the Barn Owl Caudolateral NL

Our labeling data showed the presence of a systematic, topographic representation of the ITD in the low-frequency, caudolateral region of the NL, with large best ITD located more laterally than ITD close to 0 (fig. 8). Singleunit recordings suggested an additional topography of best ITD along the dorsoventral axis; however, this was not significant for the total data population (not shown).

Regarding tonotopic organization, previous studies have found a change in frequency along the mediolateral axis of the caudolateral region of the NL [Köppl and Carr, 1997; analysis of the termination sites of labeled nucleus magnocellularis afferent axons]. This is consistent with the weak trend observed here and, together, suggests that the tonotopic organization in the caudolateral part of the NL continues the pattern known from the medial, highfrequency region [Takahashi and Konishi, 1988; Carr and Konishi, 1990]: isofrequency bands run at an angle relative to the brain's midline, from caudomedial to rostrolateral. This is also the known pattern in the chicken NL [Rubel and Parks, 1975; Köppl and Carr, 2008]. Thus, there is tentative evidence for a tonotopic organization as previously shown for other parts of the NL and other species.

The topography of the best ITD along the mediolateral axis is consistent with a chicken-like organization in which a topographic representation of the best ITD has been shown along each isofrequency band [Köppl and Carr, 2008]. Unfortunately, it was not possible to plot our data in an exactly comparable way, i.e. along the isofrequency dimension, because of the uncertainties regarding the tonotopic axis. However, a topography along the mediolateral axis, as found here, is predicted with the present plane of sectioning (fig. 9). The tentative topography of the best ITD along the dorsoventral axis that we observed for single-unit data only is not directly predicted from the chicken data; however, the chicken NL lacks this dimension over most of its extent. Intriguingly, the dorsoventral dimension is the main axis of the best ITD topography in
Table 2. Estimated natural ITD ranges for the barn owl at different frequencies and predictions for the lowest BF of NL units that could discriminate these ITD

\begin{tabular}{lll}
\hline Frequency, $\mathrm{Hz}$ & Maximal $\mathrm{ITD}^{\mathrm{b}}, \mu \mathrm{s}$ & $\begin{array}{l}\text { Predicted boundary of } \\
\text { the BFc }, \mathrm{Hz}\end{array}$ \\
\hline 8,000 & 150 & 1,525 \\
4,000 & 165 & \\
2,000 & 233 & 1,025 \\
1,500 & 210 & \\
1,000 & 233 & 550 \\
700 & 416 & 425 \\
500 & 550 & \\
\hline
\end{tabular}

a The 7 frequencies at which ITD were measured using cochlear microphonics in the grass owl T. longimembris [Calford and Piddington, 1988].

${ }^{b}$ Read from figure 3 of Calford and Piddington [1988]. The head width of the grass owl [ $42.5 \mathrm{~mm}$ in Calford and Piddington, 1988] is very similar to that of the barn owl T. alba [44-48 $\mathrm{mm}$ in Köppl et al., 2005], so the ITD ranges of the barn owl are likely to be similar as well.

${ }^{\mathrm{c}}$ Median BF above which the peak regions of idealized ITD selectivity curves of NL single units were predicted to resolve the respective ITD [fig. 4B of Fischer and Seidl, 2014].

the owl medial NL [Sullivan and Konishi, 1986; Carr and Konishi, 1990]. This is a surprising, tentative similarity that warrants further investigation.

In summary, our data provide strong evidence for a topographic representation of best ITD within each isofrequency band in the owl NL. Such an organization is a hallmark prediction of the Jeffress model. Next, we ask whether the physiology of the owl's low-frequency NL further supports a Jeffress-like coding scheme or not.

\section{Relation of ITD Distribution to the Owl's Natural Range}

In a 2-channel model of ITD coding, many best ITD values are predicted to fall outside the naturally heard range of the animal [Harper and McAlpine, 2004; Harper et al., 2014], while the Jeffress model predicts all values to fall within that range. What is this range for the barn owl? Its acoustic range of ITD was measured as \pm 250 to \pm 300 $\mu \mathrm{s}$, and it was almost invariant over a broad frequency range [Poganiatz et al., 2001; von Campenhausen and Wagner, 2006; Hausmann et al., 2010]. Estimates derived from cochlear microphonics in the closely related grass owl agree with these values at high frequencies. In contrast, significantly higher ITD ranges, i.e. up to \pm 400 and $\pm 550 \mu$ s, were found at frequencies $<1 \mathrm{kHz}$ [Calford and 
Piddington, 1988; table 2]. This is a consequence of the open, internally coupled middle ears and suggests that, at low frequencies, the ITD range actually perceived by the owl might be significantly enhanced compared to that acoustically measured in the outer ear canal [e.g. Christensen-Dalsgaard, 2005]. Although it is difficult to predict exactly what the owl's ITD range will be at even lower frequencies, it can be expected to increase further [Calford and Piddington, 1988; Larsen et al., 2006]. We thus argue that the majority of best ITD reported here fall within a plausible physiological range. Whether our largest observed values might still be physiological can only be clarified by a more thorough characterization of the ITD cues down to these low frequencies.

\section{Is ITD Coding in the Owl Different for the Low- and} High-Frequency Ranges?

Our physiological data did not show any significant deviation from what has been observed in the higher-frequency region of the barn owl NL, neither in the 800- to $3,000-\mathrm{Hz}$ frequency range, where the place code model may not be optimal any more, nor below $800 \mathrm{~Hz}$, where the presence of a population code was predicted by Harper and McAlpine [2004]. In fact, the distribution of ITD below $800 \mathrm{~Hz}$ suggests the presence of a Jeffress-like code, since the median of the best ITD distribution at those frequencies, i.e. $280 \mu \mathrm{s}$, was well within the physiological range of the barn owl. Even the interquartile range, which covered the contralateral space from 0 to $750 \mu \mathrm{s}$ (fig. $5 \mathrm{~d}$ ), is still a plausible physiological range for the barn owl at low frequencies. A model by Fischer and Seidl [2014] estimated the minimum resolvable ITD based on the peak or slope regions, respectively, of idealized single-unit ITD selectivity curves at different BF. Their results suggest that the barn owl should be able to use the peaks of ITD response curves to discriminate ITD at frequencies lower than $500 \mathrm{~Hz}$ (table 2). If the slopes had been used, which is in principle also compatible with a Jeffress-like place code, the boundary BF would have been even lower. In addition, we found evidence for a topographic representation of the best ITD. Such an organization is a hallmark of a Jeffress-like delay line model. Taking both anatomical and physiological data together, the most parsimonious interpretation is that there is no fundamental change in organization between the high- and low-frequency regions of the NL in the owl.

A likely explanation for the absence of the change predicted by the optimal code model is that the prediction assumed a physiological range for the barn owl based only on head size and disregarding the effects of internal coupling of the middle ears. This would result in an underestimation at low frequencies, where the internal coupling increases the maximum range of ITD. We conclude that physiology, topographic organization, and theory support a Jeffress-like place code of ITD in the barn owl $\mathrm{NL}$ across the entire tonotopic range. The relative role, if any, of the low-frequency NL for sound localization in the owl is a separate and interesting question for future studies.

\section{Acknowledgements}

This study was supported by the Deutsche Forschungsgemeinschaft (CRC Active Hearing, project A14). We thank Jose Luis Peña, Sharad Shanbhag, and Go Ashida for the use of and support with custom-written software. Sandra Buschhaus provided expert technical support for histology. Daniel Erlemann participated in the histological analysis as part of an undergraduate project.

\section{References}

\footnotetext{
Ashida G, Carr C (2011): Sound localization: Jef- Carr C, Konishi M (1990): A circuit for detection fress and beyond. Curr Opin Neurobiol 21: of interaural time differences in the brain 745-751. stem of the barn owl. J Neurosci 10:32273246.

- Brand A, Behrend O, Marquardt T, McAlpine D, Grothe B (2002): Precise inhibition is essential for microsecond interaural time difference coding. Nature 417:543-547.

Carr CE, Köppl C (2004): Coding interaural time differences at low best frequencies in the barn owl. J Physiol Paris 98:99-112.

Bremen P, Joris P (2013): Axonal recordings from Carr C, Soares D, Smolders J, Simon J (2009): Demedial superior olive neurons obtained from tection of interaural time differences in the althe lateral lemniscus of the chinchilla (Chin- ligator. J Neurosci 29:7978-7990. chilla laniger). J Neurosci 33:17506-17518. Cazettes F, Fischer BJ, Pena JL (2014): Spatial cue

Calford M, Piddington R (1988): Avian interaural canal enhances interaural delay. J Comp

Cheng SM, Carr C (2007): Functional delay of myelination of auditory delay lines in the nucleus laminaris of the barn owl. Dev Neurobiol 67:1957-1974.

Christensen-Dalsgaard J (2005): Directional hearing in nonmammalian tetrapods; in Popper AN, Fay RR (eds): Sound Source Localization. New York, Springer Science and Business Media, pp 67-123.

Day M, Semple M (2011): Frequency-dependent interaural delays in the medial superior olive: implications for interaural cochlear delays. J Neurophysiol 106:1985-1999. reliability drives frequency tuning in the barn owl's midbrain. Elife 3:e 04854 .
} Physiol A 162:503-510.
Barn Owl Low-Frequency NL

A


Fischer BJ, Peña JL (2009): Bilateral matching of Joris P, Yin T (2007): A matter of time: internal frequency tuning in neural cross-correlators of the owl. Biol Cybern 100:521-531.

-Fischer BJ, Seidl AH (2014): Resolution of interaural time differences in the avian sound localization circuit - a modeling study. Front Comp Neurosci 8:99.

- Fischer BJ, Steinberg LJ, Fontaine B, Brette R, Peña JL (2011): Effect of instantaneous frequency glides on interaural time difference processing by auditory coincidence detectors. Proc Natl Acad Sci USA 108:18138-18143.

Fontaine B, Brette R (2011): Neural development of binaural tuning through Hebbian learning predicts frequency-dependent best delays. J Neurosci 31:11692-11696.

Franken TP, Roberts MT, Wei L, Golding NL, Joris PX (2015): In vivo coincidence detection in mammalian sound localization generates phase delays. Nat Neurosci 18:444-452.

Funabiki K, Ashida G, Konishi M (2011): Computation of interaural time difference in the owl's coincidence detector neurons. J Neurosci 31:15245-15256.

-Galambos R, Schwartzkopff J, Rupert A (1959): Microelectrode study of superior olivary nuclei. Am J Physiol 197;527-536.

Goldberg J, Brown P (1969): Response of binaural neurons of dog superior olivary complex to dichotic tonal stimuli: some physiological mechanisms of sound localization. J Neurophysiol 32:613-636.

-Goldwyn J, McLaughlin M, Verschooten E, Joris P, Rinzel J (2014): A model of the medial superior olive explains spatio-temporal features of local field potentials. J Neurosci 34:1170511722.

Grothe B, Pecka M, McAlpine D (2010): Mechanisms of sound localization in mammals. Physiol Rev 90:983-1012.

Grothe B, Pecka M (2014): The natural history of sound localization in mammals - a story of neuronal inhibition. Front Neural Circuits 8: 116.

-Harper N, McAlpine D (2004): Optimal neural population coding of an auditory spatial cue. Nature 430:682-686.

- Harper N, Scott BH, Semple MN, McAlpine D (2014): The neural code for auditory space depends on sound frequency and head size in an optimal manner. PLoS One 9:e108154.

-Hausmann L, Von Campenhausen M, Wagner H (2010): Properties of low-frequency head-related transfer functions in the barn owl (Tyto alba). J Comp Physiol A Neuroethol Sens Neural Behav Physiol 196:601-612.

-Jeffress L (1948): A place theory of sound localization. J Comp Physiol Psych 41:35.

- Jercog PE, Svirskis G, Kotak VC, Sanes DH, Rinzel J (2010): Asymmetric excitatory synaptic dynamics underlie interaural time difference processing in the auditory system. PLoS Biol 8:e1000406. delays in binaural processing. Trends Neuro-

Köppl C (1997): Frequency tuning and spontaneous activity in the auditory nerve and cochlear nucleus magnocellularis of the barn owl, Tyto alba. J Neurophysiol 77:364-377.

Köppl C, Carr C (1997): Low-frequency pathway in the barn owl's auditory brainstem. J Comp Neurol 378:265-282.

Köppl C, Carr C (2008): Maps of interaural time difference in the chicken's brainstem nucleus laminaris. Biol Cybern 98:541-559.

Köppl C, Futterer E, Nieder B, Sistermann R, Wagner H (2005): Embryonic and posthatching development of the barn owl (Tyto alba): reference data for age determination. Dev Dyn 233:1248-1260.

Kuokkanen P, Wagner H, Ashida G, Carr C, Kempter R (2010): On the origin of the extracellular field potential in the nucleus laminaris of the barn owl (Tyto alba). J Neurophys 104:2274-2290.

Larsen ON, Dooling RJ, Michelsen A (2006): The role of pressure difference reception in the directional hearing of budgerigars (Melopsittacus undulatus). J Comp Physiol A Neuroethol Sens Neural Behav Physiol 192:1063-1072.

McAlpine D, Jiang D, Palmer A (2001): A neural code for low-frequency sound localization in mammals. Nat Neurosci 4:396-401.

-McLaughlin M, Verschooten E, Joris P (2010): Oscillatory dipoles as a source of phase shifts in field potentials in the mammalian auditory brainstem. J Neurosci 30:13472-13487.

Peña J, Viete S, Albeck Y, Konishi M (1996): Tolerance to sound intensity of binaural coincidence detection in the nucleus laminaris of the owl. J Neurosci 16:7046-7054.

Peña J, Viete S, Funabiki K, Saberi K, Konishi M (2001): Cochlear and neural delays for coincidence detection in owls. J Neurosci 21:94559459.

Poganiatz I, Nelken I, Wagner H (2001): Soundlocalization experiments with barn owls in virtual space: influence of interaural time difference on head-turning behavior. J Assoc Res Otolaryngol 2:1-21.

Quiroga R, Nadasdy Z, Ben-Shaul Y (2004): Unsupervised spike detection and sorting with wavelets and superparamagnetic clustering. Neural Comput 16:1661-1687.

Rubel E, Parks T (1975): Organization and development of brain stem auditory nuclei of the chicken: tonotopic organization of n. magnocellularis and n. laminaris. J Comp Neurol 164:411-433.

Schroeder MR (1977): New viewpoints in binaural interactions; in Evans EF, Wilson JP (eds): Psychophysics and Physiology of Hearing. New York, Academic Press, pp 455-467.

-Schwarz DW (1992): Sound delay lines in the nucleus laminaris of the chicken. J Otolaryngol 21:202-208. sci 30:70-78.
Scott L, Mathews P, Golding N (2005): Posthearing developmental refinement of temporal processing in principal neurons of the medial superior olive. J Neurosci 25:7887-7895.

- Seidl A, Rubel EW, Barria A (2014): Differential conduction velocity regulation in ipsilateral and contralateral collaterals innervating brainstem coincidence detector neurons. J Neurosci 34:4914-4919.

- Seidl A, Rubel E, Harris D (2010): Mechanisms for adjusting interaural time differences to achieve binaural coincidence detection. J Neurosci 30:70-80.

Shamma S, Shen N, Gopalaswamy P (1989): Stereausis: binaural processing without neural delays. J Acoust Soc Am 86:989-1006.

- Singheiser M, Fischer BJ, Wagner H (2010): Estimated cochlear delays in low best-frequency neurons in the barn owl cannot explain coding of interaural time difference. J Neurophys 104:1946-1954.

- Sullivan W, Konishi M (1986): Neural map of interaural phase difference in the owl's brainstem. Proc Natl Acad Sci USA 83:8400-8404.

Takahashi TT, Konishi M (1988): Projections of the cochlear nuclei and nucleus laminaris to the inferior colliculus of the barn owl. J Comp Neurol 274:190-211.

Tsuchitani C, Boudreau J (1964): Wave activity in the superior olivary complex of the cat. J Neurophysiol 27:814-827.

von Campenhausen M, Wagner H (2006): Influence of the facial ruff on the sound-receiving characteristics of the barn owl's ears. J Comp Physiol A Neuroethol Sens Neural Behav Physiol 192:1073-1082.

Vonderschen K, Wagner H (2014): Detecting interaural time differences and remodeling their representation. Trends Neurosci 37: 289-300.

-Wagner H, Asadollahi A, Bremen P, Endler F, Vonderschen $\mathrm{K}$, von Campenhausen $\mathrm{M}$ (2007): Distribution of interaural time difference in the barn owl's inferior colliculus in the low- and high-frequency ranges. J Neurosci 27:4191-4200.

-Wagner H, Mazer J, von Campenhausen M (2002): Response properties of neurons in the core of the central nucleus of the inferior colliculus of the barn owl. Eur J Neurosci 15: 1343-1352.

-Weinberger N, Kitzes L, Goodman D (1970): Some characteristics of the 'auditory neurophonic'. Experientia 26:46-48.

Wernick J, Starr A (1968): Binaural interaction in the superior olivary complex of the cat: an analysis of field potentials evoked by binaural-beat stimuli. J Neurophysiol 31:428-441.

- Yin T, Kuwada S (1983): Binaural interaction in low-frequency neurons in inferior colliculus of the cat. 3. Effects of changing frequency. J Neurophysiol 50:1020-1042. 